\title{
Thermal Conductivity and Mechanical Properties of As-Cast and As-Extruded Mg-Zn-Mn Alloys
}

\author{
Hechao Lit ${ }^{a}$, Xiangrong Zhu ${ }^{a, b *} \mathbb{D}$, Ya Zhang ${ }^{c}$, Wenxuan Tang ${ }^{a}$, Dongyun Ma ${ }^{a}$, Jinmin Wang ${ }^{a}$, Qiurong Chen \\ ${ }^{a}$ School of environmental and materials engineering, College of Engineering, Shanghai Polytechnic \\ University, Shanghai, China \\ ${ }^{b}$ Research Center of Resource Recycling Science and Engineering, Shanghai Polytechnic University, \\ Shanghai, China \\ 'Shanghai Institute of Micro-system and Information Technology, Chinese Academy of Sciences, \\ Shanghai, China
}

Received: July 15, 2019; Revised: September 29, 2019; Accepted: October 16, 2019

\begin{abstract}
As-cast and as-extruded $\mathrm{Mg}-[\mathrm{x}] \mathrm{Zn}-0.3 \mathrm{Mn}(\mathrm{x}=1.5,2.0 \mathrm{wt} . \%)$ alloys were prepared by means of medium-frequency induction-heating technique and extrusion process, respectively. The microstructural characteristics, thermal conductivity and mechanical properties of the samples were characterized. The research results show that the samples are composed of major $\alpha-\mathrm{Mg}$ and minor second phases $\mathrm{MgZn}_{2}$. For the as-extruded samples, the grain size is refined. After extrusion, much more second phases were precipitated from $\alpha-\mathrm{Mg}$ matrix and the dislocations were reduced. The degree of lattice distortion was decreased for as-extruded samples. Because of the decline of lattice distortion degree, the as-extruded samples display much higher thermal conductivity than the as-cast samples. Additionally, on account of lower lattice distortion, $\mathrm{Mg}-1.5 \mathrm{Zn}-0.3 \mathrm{Mn}$ alloy has a bit larger thermal conductivity than $\mathrm{Mg}-2 \mathrm{Zn}-0.3 \mathrm{Mn}$ alloy. Finally, the as-extruded alloys present good mechanical properties based on the fine-grained strengthening and second-phase strengthening mechanism.
\end{abstract}

Keywords: Microstructure, thermal conductivity, mechanical properties, magnesium alloys.

\section{Introduction}

Magnesium alloys have attracted more and more attention due to their excellent application properties which include high specific strength for light structural materials and proper thermal conductivity ${ }^{1-6}$. Among the magnesium alloys, Mg-Zn based alloys are one kind of the most widely used magnesium alloys ${ }^{7,8}$. The addition of $\mathrm{Zn}$ plays the role in solution strengthen. Ying et al. studied the thermal characteristics of $\mathrm{Mg}-\mathrm{Zn}$ alloys and found that the thermal conductivity of the alloys decreased remarkably with increasing Zn composition ${ }^{9}$. Pan et al. reported the thermal conductivity of $\mathrm{Mg}-\mathrm{Zn}$ alloys at room temperature. Their results also showed that thermal conductivity decreased with the increasing content of $\mathrm{Zn}$. The additive amount of $\mathrm{Zn}$ for moderate thermal conductance should be around $2 \mathrm{wt} . \%{ }^{10}$.

Furthermore, other element such as Mn could play an important role in improving the properties of $\mathrm{Mg}$ alloys. As an alloying additive, Mn can enhance heat resistance of the Mg alloys and refine the grain size. Recently, it was reported that the addition of $\mathrm{Mn}$ element can improve the mechanical properties of $\mathrm{Mg}-\mathrm{Zn}-\mathrm{Al}$, and the $\mathrm{Mn}$ addition amount for good mechanical properties is about $0.4 \mathrm{wt} . \%{ }^{11}$.

From the application point of view, besides good thermal conductivity, the mechanical properties of magnesium alloys are also very important. The mechanical properties can be further increased by deformation processing such as extrusion.
Begum et al. found that mechanical properties of AZ31 magnesium alloy can be improved by extrusion ${ }^{12}$. Homma et al. fabricated high-strength $\mathrm{Mg}-\mathrm{Gd}-\mathrm{Y}-\mathrm{Zn}-\mathrm{Zr}$ alloys by extrusion ${ }^{13}$.

Especially, the properties of magnesium alloys are related to their microstructural characteristics including dislocations, grain boundaries and second phases, which are strongly affected by the addition of alloy elements and deformational processing. Nowadays, the researches of the properties of Mg-Zn-Mn alloys are mostly focused on the mechanical properties ${ }^{14-15}$. There are few reports about thermal properties of $\mathrm{Mg}-\mathrm{Zn}-\mathrm{Mn}$ alloys with variable $\mathrm{Zn}$ content.

In this paper, the as-cast and as-extruded $\mathrm{Mg}-[\mathrm{x}] \mathrm{Zn}-0.3 \mathrm{Mn}$ $(\mathrm{x}=1.5,2.0 \mathrm{wt}$. \%) samples were prepared. Their microstructure, thermal conductivity and mechanical properties were characterized. The correlation between thermal conductivity, mechanical properties and microstructure was discussed to reveal the mechanism of high thermal conductivity and mechanical properties for the as-extruded samples.

\section{Experimental Procedures}

Commercial high-purity $\mathrm{Mg}$ (>99.98 wt.\%), Zn (>99.95 wt.\%), and one kind of master alloy (Mg-5.2 wt.\% Mn) were used to fabricate the magnesium alloy samples. The nominal composition of the alloys was designed as $\mathrm{Mg}-1.5 \mathrm{Zn}-0.3 \mathrm{Mn}$ (marked as $1 \#$ ) and $\mathrm{Mg}-2 \mathrm{Zn}-0.3 \mathrm{Mn}$ (marked as $2 \#$ ) respectively. The as-cast $\mathrm{Mg}$ alloy ingots were prepared by medium-frequency induction-heating technique. 
The size of the ingots was $\varphi 120 \mathrm{~mm} \times 400 \mathrm{~mm}$. The chemical composition of the ingots was measured via an Aglient-5100 ICP-OES. The analyzed results of the composition are listed in Table 1. According to Table 1, the true $\mathrm{Zn}$ content of the ingots has less than $20 \%$ deviation to the nominal composition.

Table 1. Chemical compositions of the Mg alloy samples

\begin{tabular}{cccc}
\hline \multirow{2}{*}{ Nominal alloys } & \multicolumn{4}{c}{ Measured composition (wt.\%) } \\
\cline { 2 - 4 } & $\mathbf{Z n}$ & $\mathbf{M n}$ & Mg \\
\hline $\mathrm{Mg}-1.5 \mathrm{Zn}-0.3 \mathrm{Mn}(1 \#)$ & 1.71 & 0.35 & $\mathrm{Bal}$. \\
$\mathrm{Mg}-2 \mathrm{Zn}-0.3 \mathrm{Mn}(2 \#)$ & 2.37 & 0.36 & $\mathrm{Bal}$. \\
\hline
\end{tabular}

Some of the as-cast alloy ingots were extruded in boards to obtain as-extruded alloy samples. The extruding board size was $2000 \mathrm{~mm}$ in length, $70 \mathrm{~mm}$ in width and $10 \mathrm{~mm}$ in thickness (cross section). The extrusion processing was as follows: extrusion temperature $673 \mathrm{~K}$, extrusion ratio 9:1 and extrusion rate $2 \mathrm{~mm} / \mathrm{s}$. After extrusion, the samples were cooled in air.

Measurement of crystal structure of the as-cast and asextruded alloy samples and phase analysis were performed via one $\mathrm{X}$-ray diffraction meter with a $\mathrm{Cu}$ target. Microstructural morphology of the alloy samples was observed via one optical microscope (OM) and one transmission electron microscope (TEM).

The room temperature density of the samples was obtained by AL204 electronic balance, and the density at elevated temperatures was calculated using the following Eq. (1) .

$$
p=p_{0}-0.156(T-298)
$$

Where $\rho_{0}\left(\mathrm{~kg} / \mathrm{m}^{3}\right)$ is the density at room temperature, $\mathrm{T}$ $(\mathrm{K})$ is the absolute temperature ${ }^{16}$. The density data of the samples at temperatures ranging from $298 \mathrm{~K}$ to $573 \mathrm{~K}$ are shown in Table 2.

The samples for thermal properties measurement were disks cut from the as-cast and as-extruded alloys, $12.7 \mathrm{~mm}$ in diameter and $2.5 \mathrm{~mm}$ in thickness. The thermal diffusivity $(\alpha)$ and specific heat capacity $(\mathrm{Cp})$ of the alloy samples were measured at temperatures ranging from $298 \mathrm{~K}$ to $573 \mathrm{~K}$ via an NETZSCH LFA467 flash analyzer.
Then the thermal conductivity $(K)$ was calculated via the following Eq. (2):

$$
K=C_{p} \cdot a \cdot p
$$

where $\mathrm{K}(\mathrm{W} / \mathrm{m} \cdot \mathrm{K})$ is the thermal conductivity, $\mathrm{Cp}(\mathrm{J} / \mathrm{kg} \cdot \mathrm{K})$ is the specific heat capacity, $\alpha\left(\mathrm{m}^{2} / \mathrm{s}\right)$ is thermal diffusivity and $\rho\left(\mathrm{kg} / \mathrm{m}^{3}\right)$ is the density ${ }^{16}$.

The mechanical properties measurements were conducted via one universal tensile testing machine. For the as-extruded samples, the tensile specimens were machined along the extrusion direction (ED) with a gauge length of $50 \mathrm{~mm}$ and a cross-sectional size of $6 \times 2 \mathrm{~mm}$. The tensile tests were carried out at a tensile rate of $1 \mathrm{~mm} / \mathrm{min}$ at room temperature.

\section{Results and Discussion}

\subsection{Microstructure analysis}

Fig. 1 shows the XRD patterns of the alloy samples. It can be seen from Fig. 1 that the phases of the as-cast and asextruded alloys are composed of major $\alpha-\mathrm{Mg}$ solid solutions. The peaks of $\mathrm{MgZn}_{2}$ phases are also displayed. However, the strength of $\mathrm{MgZn}_{2}$ phases is very weak, implying that the $\mathrm{MgZn}_{2}$ phases are second phases and the amount of $\mathrm{MgZn}_{2}$ phases is much less. In addition, it is noteworthy that it is difficult to compare the content of $\mathrm{MgZn}_{2}$ phase in each sample according to the XRD spectra.

Fig. 2 shows the optical micrographs of the as-cast and as-extruded Mg-xZn-0.3Mn alloys. As shown in Fig. 2 (a) and Fig. 2 (b), the alloys phases are mostly composed of $\alpha-\mathrm{Mg}$ matrix. Some little second phases are distributed in the grains of $\alpha-\mathrm{Mg}$. Based on the former XRD results, the second phases should be $\mathrm{MgZn}_{2}$. In the process of preparing as-cast alloy, if the content of $\mathrm{Zn}$ in solid solution was supersaturated, $\mathrm{MgZn}_{2}$ phase would precipitate when the sample was cooled ${ }^{17}$. Besides, it is observed that the grain size of as-cast alloys with two components is not significantly different. After extrusion, as shown in Fig. 2 (c) and Fig.2 (d), the average grain size obviously decreased. In the extrusion process, the temperature was kept at $673 \mathrm{~K}$, which exceeded the recrystallization temperature of magnesium alloy, about $525 \mathrm{~K}$. Therefore, recrystallization would occur during extrusion.

\begin{tabular}{|c|c|c|c|c|c|c|c|}
\hline & & \multicolumn{6}{|c|}{ Density $\left(\mathrm{kg} / \mathrm{m}^{3}\right)$} \\
\hline \multicolumn{2}{|c|}{ Alloys } & \multicolumn{6}{|c|}{$\mathbf{T}(\mathbf{K})$} \\
\hline & & 298 & 373 & 423 & 473 & 523 & 573 \\
\hline \multirow{2}{*}{$\mathrm{Mg}-1.5 \mathrm{Zn}-0.3 \mathrm{Mn}$} & as-cast & 1745 & 1733 & 1725 & 1718 & 1710 & 1702 \\
\hline & as-extruded & 1749 & 1737 & 1729 & 1722 & 1714 & 1706 \\
\hline \multirow{2}{*}{$\mathrm{Mg}-2.0 \mathrm{Zn}-0.3 \mathrm{Mn}$} & as-cast & 1751 & 1739 & 1731 & 1724 & 1716 & 1708 \\
\hline & as-extruded & 1754 & 1742 & 1734 & 1727 & 1719 & 1711 \\
\hline
\end{tabular}

Table 2. Densities of the Mg-xZn-0.3Mn alloys 

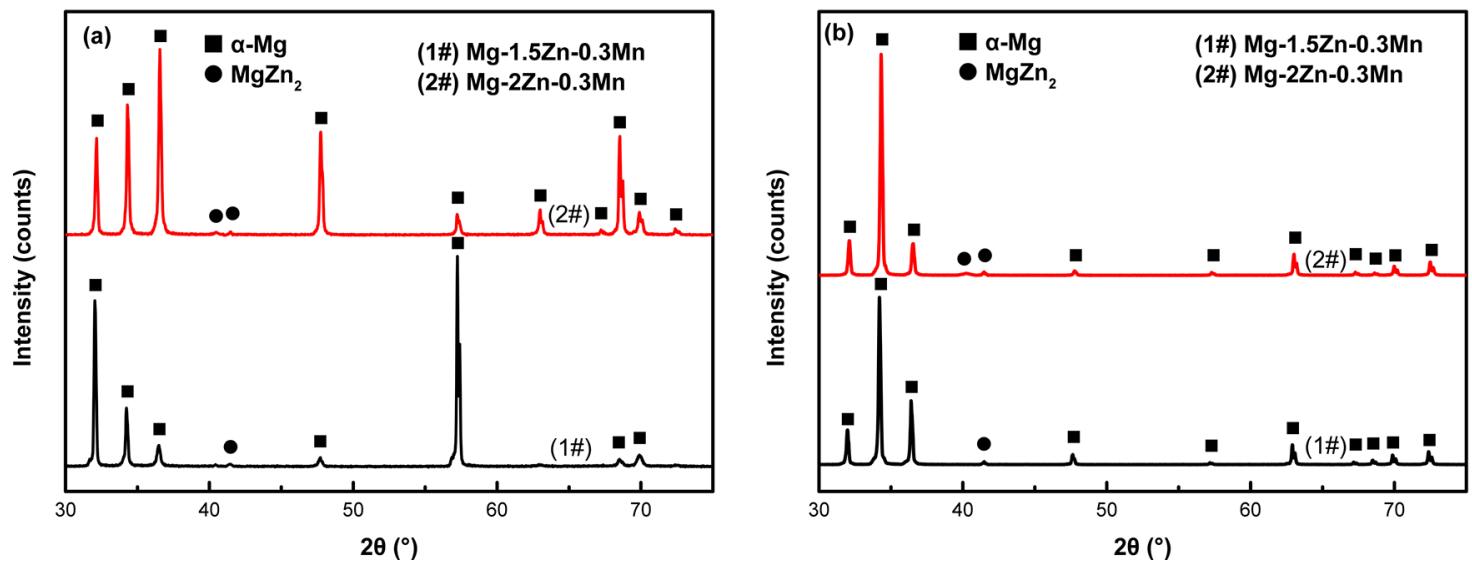

Figure 1. XRD patterns of Mg-xZn-0.3Mn alloys.(a) as-cast samples, (b) as-extruded samples.
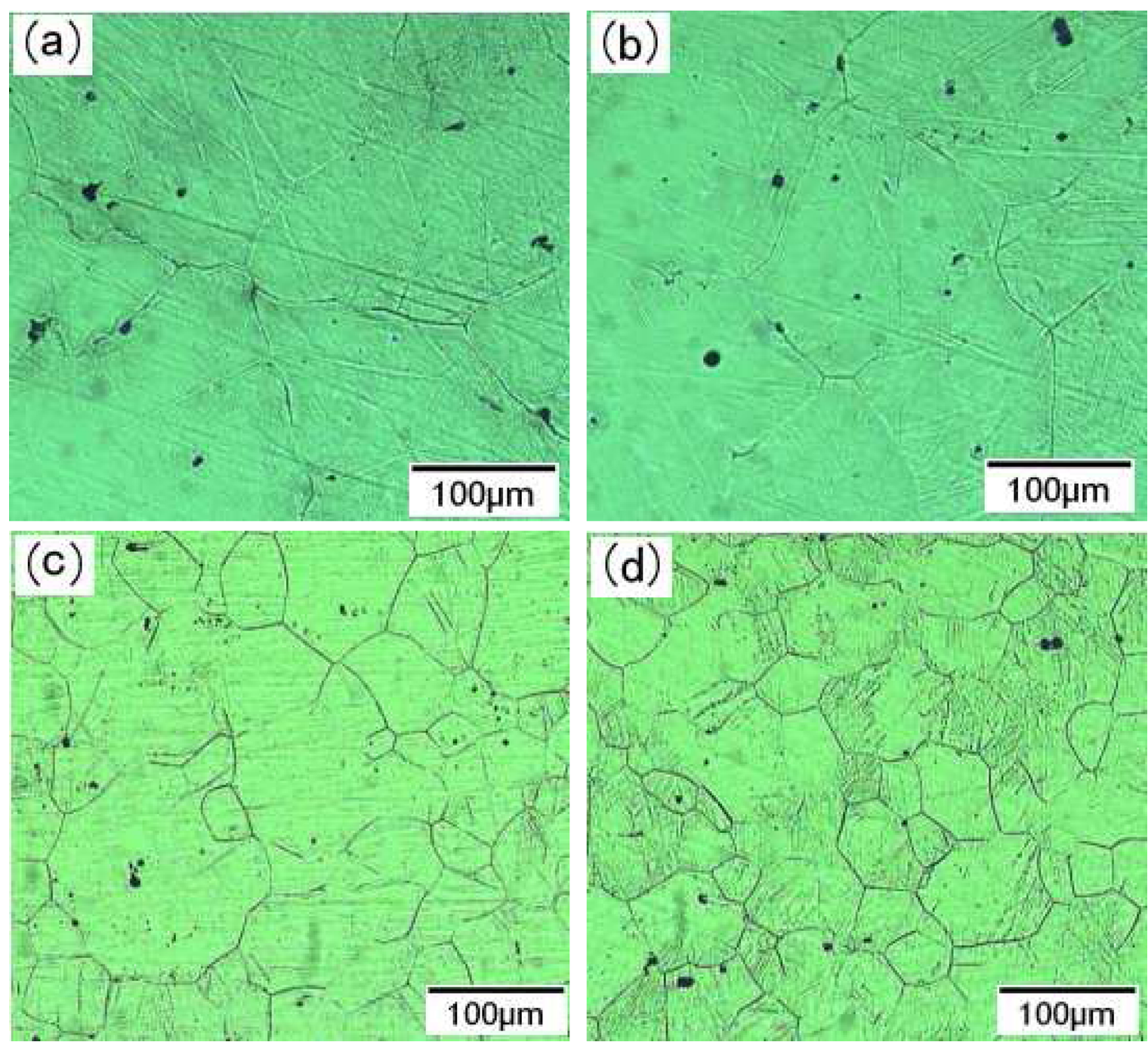

Figure 2. Optical micrographs of the as-cast alloys (a) Mg-1.5Zn-0.3Mn (1\#), (b) Mg-2Zn-0.3Mn (2\#), optical micrographs of the asextruded alloys (c) Mg-1.5Zn-0.3Mn (1\#), (d) Mg-2Zn-0.3Mn (2\#). 
Recrystallization resulted in significant refinement of the grains ${ }^{9,18,19}$. Furthermore, comparing with the as-cast samples, the size of second phases in the as-extruded samples diminished and their amount became more. According to the analysis results of the phase analysis tool software of metallographic microscope, for as-cast samples, the proportion of the second phase in the surface of 1 \# and 2 \# samples was $0.58 \%$ and $0.71 \%$ respectively. For as-extruded samples, the proportion of the second phase in the surface of $1 \#$ and $2 \#$ samples increased to $1.15 \%$ and $1.52 \%$ respectively.

Fig. 3 shows the TEM images of the Mg alloy samples. As shown in Fig. 3 (a) and Fig. 3 (b), many dislocations appeared in the as-cast alloy samples. Usually the dislocations were firstly caused by the inhomogeneous diffusion of atoms such as $\mathrm{Mg} 、 \mathrm{Zn}$ and Mn during the melting process. Secondly, the solidification process of as-cast alloy was fast and belonged to non-equilibrium solidification, leading to the formation of more dislocations in the ascast alloys ${ }^{17}$. After extrusion, as shown in Fig. 3 (c) and Fig. 3 (d), the amount of dislocations greatly decreased. As described earlier, the extrusion temperature reached $673 \mathrm{~K}$.
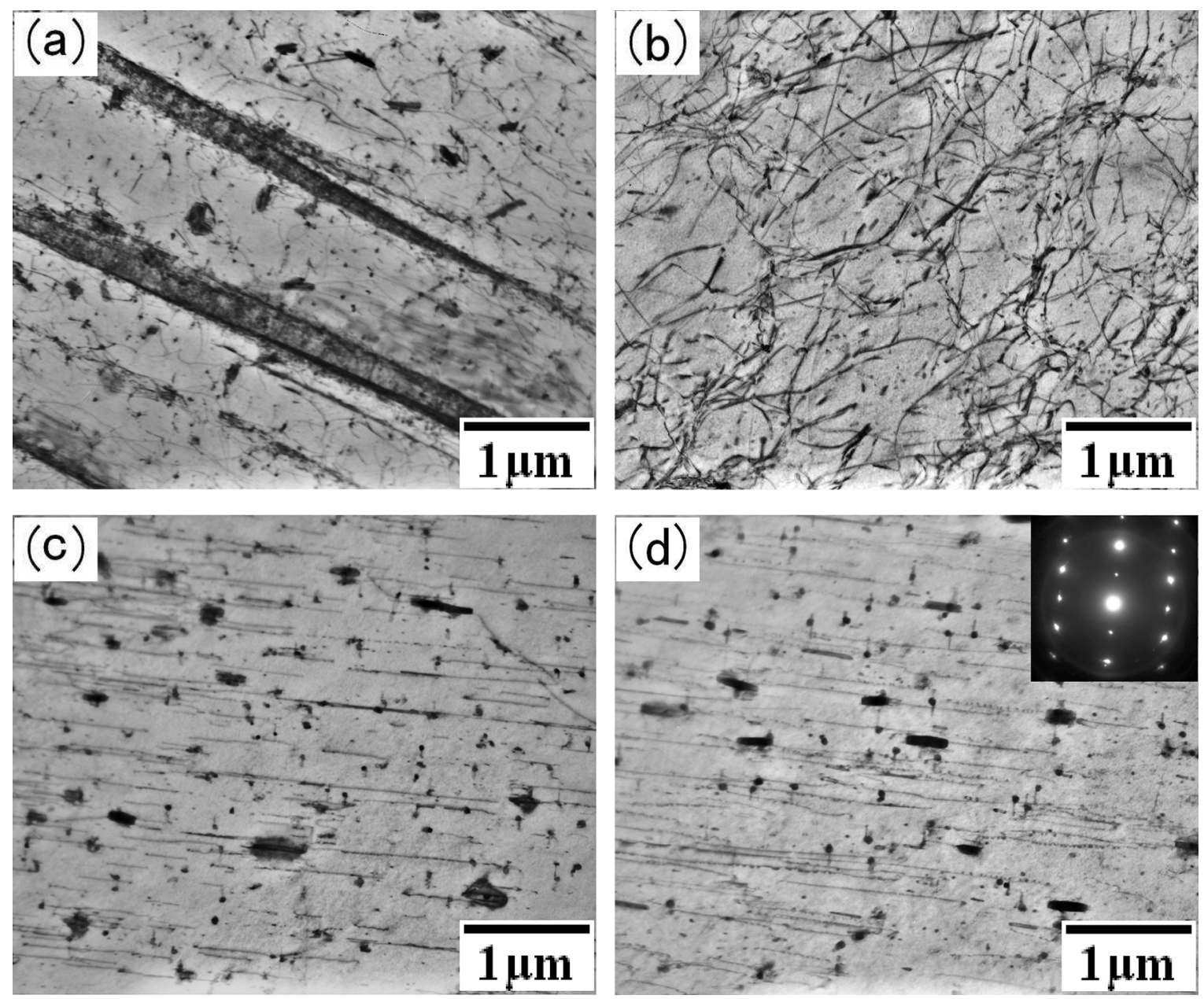

Figure 3. TEM images of the as-cast alloys (a) $\mathrm{Mg}-1.5 \mathrm{Zn}-0.3 \mathrm{Mn}$, (b) $\mathrm{Mg}-2 \mathrm{Zn}-0.3 \mathrm{Mn}$, and TEM images of the as-extruded alloys (c)

$\mathrm{Mg}-1.5 \mathrm{Zn}-0.3 \mathrm{Mn}$, (d) Mg-2Zn-0.3Mn (inset: lattice diffraction pattern of MgZn2 phase ).

At this temperature, atomic diffusion was sufficient to fill the crystal defects, which led to the reduction of dislocations ${ }^{17}$. In addition, much more second phases precipitated from $\alpha-\mathrm{Mg}$ matrix. According to the lattice diffraction pattern of the second phases shown in the inset in fig. 3(d), the second phases are just $\mathrm{MgZn}_{2}$. Usually the $\mathrm{Zn}$ in the solid solution of as-cast samples still had a certain degree of supersaturation. In the hot extrusion process, the diffusion of atoms was more sufficient. The supersaturated $\mathrm{Zn}$ atoms in the solid solution precipitated in the form of the second phase $\mathrm{MgZn}_{2}{ }^{17}$. Therefore, more second phases would appear in the as-extruded samples.

Table 3 gives the lattice constants and lattice distortion data of the Mg alloy samples based on the XRD results. The lattice constants of pure magnesium are $\mathrm{a}_{0}=3.209$ $\AA, \mathrm{c}_{0}=5.211 \AA$. Usually the lattice distortion is dominated by the content of solute atoms. Higher solute atom content in $\mathrm{Mg}$ matrix can lead to greater degree of lattice distortion $^{6}$. Thus for $1 \#$ sample with lower $\mathrm{Zn}$ content, the lattice distortion degree is lower than that of $\mathrm{Mg}-2.0 \mathrm{Zn}$ $0.3 \mathrm{Mn}$. Furthermore, the lattice distortion degree for asextruded samples is lower than that for as-cast samples.

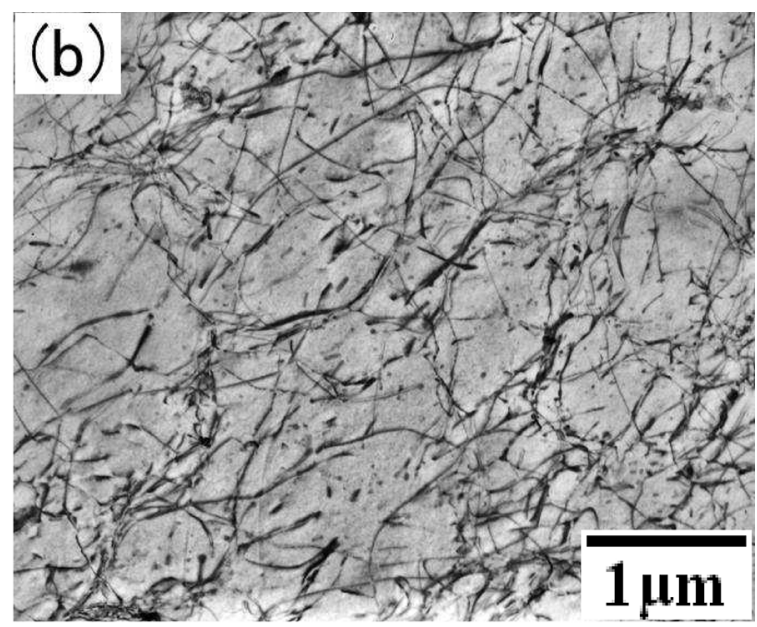


Table 3. The lattice constants of the Mg-xZn-0.3Mn alloysa

\begin{tabular}{lccccc}
\hline & Alloys & a & (a-a0)/ a0 & c & (c-c0)/ c0 \\
\hline \multirow{2}{*}{ As-cast } & Mg-1.5Zn-0.3Mn & 3.237 & $0.861 \%$ & 5.251 & $0.764 \%$ \\
& $\mathrm{Mg}-2.0 \mathrm{Zn}-0.3 \mathrm{Mn}$ & 3.243 & $1.048 \%$ & 5.266 & $1.052 \%$ \\
\multirow{3}{*}{ As-extruded } & $\mathrm{Mg}-1.5 \mathrm{Zn}-0.3 \mathrm{Mn}$ & 3.219 & $0.300 \%$ & 5.221 & $0.188 \%$ \\
& $\mathrm{Mg}-2.0 \mathrm{Zn}-0.3 \mathrm{Mn}$ & 3.229 & $0.612 \%$ & 5.239 & $0.533 \%$ \\
\hline
\end{tabular}

As discussed on Fig. 2 and Fig. 3, more second phases precipitated from $\alpha-\mathrm{Mg}$ matrix after extrusion. Then the content of the solute atoms such as $\mathrm{Zn}$ would decrease in $\alpha-\mathrm{Mg}$ matrix, which resulted in the declined lattice distortion degree for the as-extruded samples.

It should be pointed out that dislocations in crystals also increase the degree of lattice distortion ${ }^{17}$. As shown in Fig. 3, the dislocation density in the as-extruded samples decreased greatly, which also led to the improvement of the lattice distortion of the samples. Moreover, it is noteworthy that by further comparing the lattice distortion of $1 \#$ and $2 \#$ samples, it is found that the improvement degree of lattice distortion of 2 \# samples is less than that of 1 \# samples after transformation from as-cast to as-extruded.

\subsection{Thermal conductivity}

Fig. 4 shows the temperature dependence of the thermal conductivity of the samples. It can be seen from Fig. 4 that the thermal conductivity of all samples gradually increased with temperature. This phenomenon conforms to the rule that the thermal conductivity of metal material varies with temperature. Usually, the heat conductance is determined by the movements of free electrons and phonons. With rising temperature, the average velocities of both free electrons and phonons movement increase. Then the thermal conductivity goes up ${ }^{16}$.

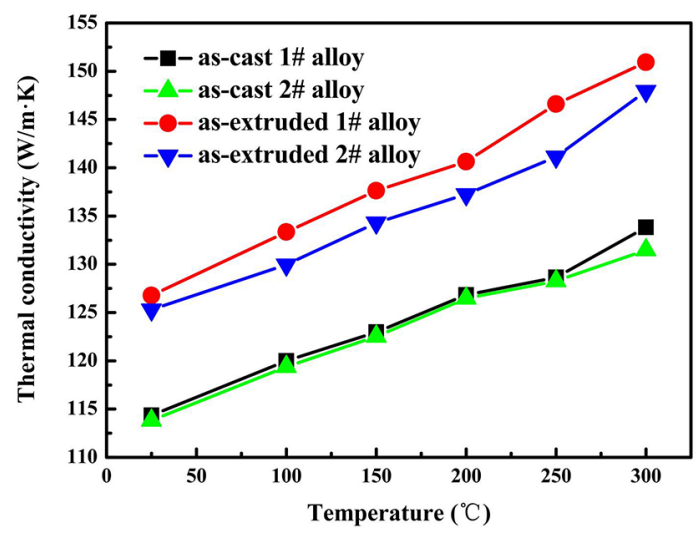

Figure 4. Temperature dependence of thermal conductivity of Mg$1.5 \mathrm{Zn}-0.3 \mathrm{Mn}$ alloy (sample $1 \#$ ) and $\mathrm{Mg}-2 \mathrm{Zn}-0.3 \mathrm{Mn}$ alloy (sample 2\#)

The results of Fig. 4 further reveal the difference of $\mathrm{Mg}-\mathrm{XZn}-0.3 \mathrm{Mn}$ alloys in thermal conduction. Firstly, for the as-cast samples, the thermal conductivity of $\mathrm{Mg}-2 \mathrm{Zn}$ $0.3 \mathrm{Mn}$ alloy is slightly lower than $\mathrm{Mg}-1.5 \mathrm{Zn}-0.3 \mathrm{Mn}$ alloy.
Usually, in metal materials, lattice distortion has a strong effect on thermal conductivity. As shown by Table 3, for Mg-2Zn-0.3Mn sample with higher $\mathrm{Zn}$ content, the lattice distortion degree is a bit higher than that of $\mathrm{Mg}-1.5 \mathrm{Zn}-0.3 \mathrm{Mn}$. If the lattice distortion degree was high, the movement of electrons and phonons would be hindered ${ }^{6}$. Then the thermal conductivity would be reduced.

Secondly, after extrusion, the thermal conductivity of the samples is obviously improved, compared with the as-cast samples. This result differs from those of other researchers. Ying et al reported that the thermal conductivity of the asextruded Mg-Zn alloy was lower than the as-cast alloy, which was attributed to the increased grain boundaries induced by extrusion ${ }^{9}$. The grain boundary was considered as the main effect factor on thermal conductance. In our study, the grain size of the as-extruded sample was reduced. This may lead to a decrease in the thermal conductivity of the sample. However, according to the results discussed above, the lattice distortion of the as-extruded samples was greatly reduced. In the case of lattice distortion, electrons or phonons will be scattered strongly, which leads to the decrease of thermal conductivity ${ }^{6}$. Therefore, the effect of grain size reduction was offset and the thermal conductivity of the as-extruded samples increased due to the declined lattice distortion. Our results show that the thermal conductivity of materials depends very much on the microstructural properties of materials.

It is noteworthy that the difference of thermal conductivity between the two as-extruded samples is more obvious, compared with the as-cast samples. This is because the improvement of lattice distortion of 1 \# as-extruded sample is higher than that of 2 \# as-extruded sample, as indicated in Table 3.

Especially, at room temperature, the thermal conductivity of as-extruded Mg-1.5Zn-0.3Mn (1\#) and Mg-2Zn-0.3Mn (2\#) alloys reaches $126.7 \mathrm{~W} /(\mathrm{m} \cdot \mathrm{K})$ and $125.2 \mathrm{~W} /(\mathrm{m} \cdot \mathrm{K})$, respectively, which increase by $10.5 \%$ and $10.2 \%$ compared with the corresponding as-cast samples.

\subsection{Mechanical properties}

Fig. 5 gives the engineering stress - strain curves of as-cast and as-extruded $\mathrm{Mg}-\mathrm{xZn}-0.3 \mathrm{Mn}$ samples. It can be seen that the mechanical properties of the as-cast samples are much lower than those of as-extruded samples. This means that the as-cast samples are difficult to use as engineering materials. It can be noticed that, the yield strength (YS), ultimate tensile strength (UTS) and tensile elongation (EL) of the as-extruded Mg-1.5Zn-0.3Mn (1\#) alloy are $155.97 \mathrm{MPa}, 258.78 \mathrm{MPa}, 11.73 \%$, respectively. 


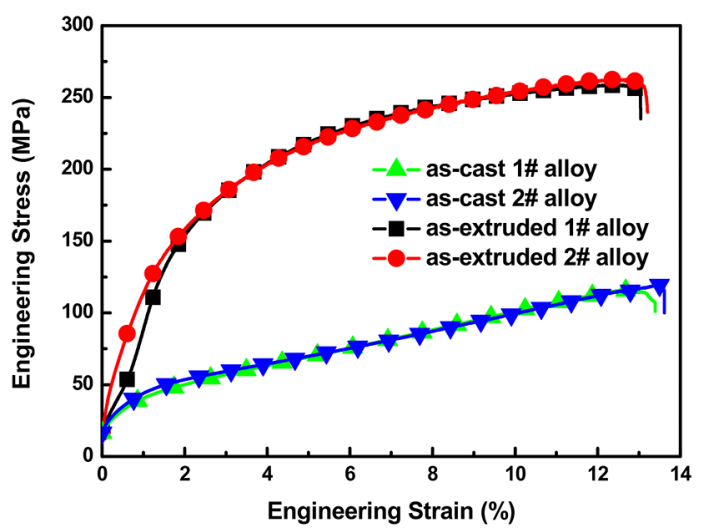

Figure 5. The engineering stress-strain curves of as-cast and asextruded Mg-xZn-0.3Mn (1\#: Mg-1.5Zn-0.3Mn, 2\#: Mg-2Zn-0.3Mn)

The YS, UTS and EL of the as-extruded Mg-2Zn- $0.3 \mathrm{Mn}$ (2\#) are $161.0 \mathrm{MPa}, 260.19 \mathrm{MPa}$ and $12.28 \%$, respectively. These results are apparently superior to the as-cast samples. On the one hand, as shown in Fig. 2, after extrusion, the grain size of the samples was significantly reduced, which then leads to the fine-grained strengthening ${ }^{6}$. According to Hall-Petch empirical formula, the finer the grain size of metal material, the higher its strength, that is to say, the effect of fine-grained strengthening is formed ${ }^{17}$. On the other hand, the as-extruded alloy has more second phases including $\mathrm{MgZn}_{2}$ phases. The second phases can play the role in second-phase strengthening, which is related to the dislocations. There are still a number of dislocations in the as-extruded samples. The interaction between the dislocations and the second phases dispersed in the grains hinders the dislocation movement and improves the deformation resistance of the alloys ${ }^{17}$. Thus the enhanced mechanical properties could be ascribed to both fine-grained strengthening and second-phase strengthening. It should be pointed out that the mechanical properties of the two as-cast samples with different compositions are similar. The same is true for the as-extruded samples. This may be because the grain size difference between the samples is not obvious, and the second phase distribution difference is not large enough.

\section{Conclusion}

The microstructure, thermal conductivity and mechanical properties of the as-cast and as-extruded $\mathrm{Mg}$-[x] wt.Zn$0.3 \mathrm{Mn}(\mathrm{x}=1.5,2.0)$ alloys were investigated in detail. The main results are summarized as follows.

1) For the samples after extrusion, the grains became smaller. Much more second phases precipitated from $\alpha-\mathrm{Mg}$ matrix and the dislocations amount reduced compared to the as-cast samples.

2) Due to the appearance of more second phases and great decrease of dislocations, the degree of lattice distortion decreased after extrusion. The lattice distortion of $\mathrm{Mg}-1.5 \mathrm{Zn}-0.3 \mathrm{Mn}$ is lower than that of Mg-2.0Zn-0.3Mn.
3) The as-extruded samples present enhanced thermal conductivity compared with the as-cast samples. Mg- $1.5 \mathrm{Zn}-0.3 \mathrm{Mn}$ alloy exhibits a bit larger thermal conductivity than $\mathrm{Mg}-2 \mathrm{Zn}-0.3 \mathrm{Mn}$ alloy. The decline of lattice distortion degree is the dominant factor for the enhancement of thermal conductivity.

4) Fine-grained strengthening and second-phase strengthening are responsible for the good mechanical properties of as-extruded Mg-xZn-0.3Mn alloys.

\section{Acknowledgements}

This work was supported by National Natural Science Foundation of China (NSFC) (No. 61775131), Program for Professor of Special Appointment (Eastern Scholar) at Shanghai Institutions of Higher Learning (No. 2013-70), Gaoyuan Discipline of Shanghai-Environmental Science and Engineering (Resource Recycling Science and Engineering), the graduate fund program (EGD17YJS029), the Key Subject Construction Project (Material Science, XXKZD1601) from Shanghai Polytechnic University and the program funded by Jiangsu Zhongke Yamei New Materials Technology Co. Ltd.

\section{References}

1. Ramaiyan S, Santhanam SKV, Muthuguru P. Effect of Scroll Pin Profile and Tool Rotational Speed on Mechanical Properties of Submerged Friction Stir Processed AZ31B Magnesium Alloy. Materials Research. 2018;21(3):e20170769. DOI: http://dx.doi. org/10.1590/1980-5373-MR-2017-0769

2. Álvarez-Leal M, Orozco-Caballero A, Carreño F, Ruano OA. Superplasticity in a commercially extruded ZK30 magnesium alloy. Materials Science and Engineering: A. 2018;710:240-244. DOI: http://dx.doi.org/10.1016/j.msea.2017.10.093

3. Richmire S, Hall K, Haghshenas M. Design of experiment study on hardness variations in friction stir welding of AM60 Mg alloy. Journal of Magnesium and Alloys. 2018;6(3):215-228. DOI: https://doi.org/10.1016/j.jma.2018.07.002

4. Peng J, Zhong L, Wang Y, Lu Y, Pan F. Effect of extrusion temperature on the microstructure and thermal conductivity of $\mathrm{Mg}-2.0 \mathrm{Zn}$ 1.0Mn-0.2Ce alloys. Materials and Design. 2015;87:914-919. DOI: https://doi.org/10.1016/j.matdes.2015.08.043

5. Rudajevová A, Von Buch F, Mordike BL. Thermal diffusivity and thermal conductivity of $\mathrm{MgSc}$ alloys. Journal of Alloys and Compounds. 1999;292(1-2):27-30. DOI: https://doi.org/10.1016/S09258388(99)00444-2

6. Zhong L, Peng J, Li M, Wang YJ, Lu Y, Pan F. Effect of Ce addition on the microstructure, thermal conductivity and mechanical properties of Mg-0.5Mn alloys. Journal of Alloys and Compounds. 2016;661:402-410. DOI: https://doi.org/10.1016/j.jallcom.2015.11.107

7. Gao X, Nie JF. Characterization of strengthening precipitate phases in a Mg-Zn alloy. Scripta Materialia. 2007;56(8):645648. DOI: https://doi.org/10.1016/j.scriptamat.2007.01.006

8. Gao X, Nie JF. Structure and thermal stability of primary intermetallic particles in an Mg-Zn casting alloy. Scripta Materialia. 2007;57(7):655658. DOI: https://doi.org/10.1016/j.scriptamat.2007.06.005 
9. Ying T, Zheng MY, Li ZT, Qiao XG, Xu SW. Thermal conductivity of as-cast and as-extruded binary $\mathrm{Mg}$ - $\mathrm{Zn}$ alloys. Journal of Alloys and Compounds. 2015;621:250-255. DOI: https://doi.org/10.1016/j.jallcom.2014.09.199

10. Pan H, Pan F, Yang R, Peng J, Zhao C, She J, et al. Thermal and electrical conductivity of binary magnesium alloys. Journal of Materials Science. 2014;49(8):3107-3124. DOI: https://doi. org/10.1007/s10853-013-8012-3

11. Khan SA, Miyashita Y, Mutoh Y, Sajuri ZB. Influence of Mn content on mechanical properties and fatigue behavior of extruded Mg alloys. Materials Science and Engineering: A. 2006;420(1-2):315-321. DOI: https://doi.org/10.1016/j. msea.2006.01.091

12. Begum S, Chen DL, Xu S, Luo AA. Low cycle fatigue properties of an extruded AZ31 magnesium alloy. International Journal of Fatigue. 2009;31(4):726-735. https://doi.org/10.1016/j. ijfatigue.2008.03.009

13. Homma T, Kunito N, Kamado S. Fabrication of extraordinary high-strength magnesium alloy by hot extrusion. Scripta Materialia. 2009;61(6):644-647. DOI: https://doi.org/10.1016/j. scriptamat.2009.06.003
14. Tahreen N, Zhang DF, Pan FS, Jiang XQ, Li DY, Chen DL. Hot deformation and processing map of an as-extruded $\mathrm{Mg}-\mathrm{Zn}$ $\mathrm{Mn}-\mathrm{Y}$ alloy containing I and $\mathrm{W}$ phases. Materials and Design. 2015;87:245-255. DOI: https://doi.org/10.1016/j.matdes.2015.08.023

15. Tahreen N, Zhang DF, Pan F, Jiang XQ, Li C, Li DY, et al. Characterization of hot deformation behavior of an extruded Mg-Zn-Mn-Y alloy containing LPSO phase. Journal of Alloys and Compounds. 2015;644:814-823. DOI: https://doi.org/10.1016/j.jallcom.2015.04.144

16. Mills KC. Recommended values of thermophysical properties for selected commercial alloy. Cambridge: Woodhead Publishing; 2002.

17. Hu GX, Cai X, Rong YH. Fundamentals of Materials Science. Shanghai, China: Shanghai Jiao Tong University Press; 2010.

18. Mishra RK, Gupta AK, Rao PR, Sachdev AK, Kumar AM, Luo AA. Influence of cerium on the texture and ductility of magnesium extrusions. Scripta Materialia. 2008;59(5):562565. DOI: https://doi.org/10.1016/j.scriptamat.2008.05.019

19. Wen K, Liu K, Wang Z, Li S, Du W. Effect of microstructure evolution on mechanical property of extruded $\mathrm{Mg}-12 \mathrm{Gd}-$ 2Er-1Zn-0.6Zr alloys. Journal of Magnesium and Alloys. 2015;3(1):23-28. DOI: https://doi.org/10.1016/j.jma.2014.12.003 